\title{
Salicylic acid signal transduction: the initiation of biosynthesis, perception and transcriptional reprogramming
}

\author{
Carolin Seyfferth and Kenichi Tsuda* \\ Department of Plant Microbe Interactions, Max Planck Institute for Plant Breeding Research, Cologne, Germany
}

\section{Edited by:}

Hua Lu, University of Maryland at Baltimore County, USA

\section{Reviewed by:}

Murray Grant, University of Exeter, UK

Zhixiang Chen, Purdue University, USA

\section{*Correspondence:}

Kenichi Tsuda, Department of Plant

Microbe Interactions, Max Planck Institute for Plant Breeding

Research, Carl-von-Linné-Weg 10, D-50829 Cologne, Germany

e-mail: tsuda@mpipz.mpg.de
The phytohormone salicylic acid (SA) is a small phenolic compound that regulates diverse physiological processes, in particular plant resistance against pathogens. Understanding SA-mediated signaling has been a major focus of plant research. Pathogen-induced SA is mainly synthesized via the isochorismate pathway in chloroplasts, with ICS1 (ISOCHORISMATE SYNTHASE 1) being a critical enzyme. Calcium signaling regulates activities of a subset of transcription factors thereby activating nuclear ICS1 expression. The produced SA triggers extensive transcriptional reprogramming in which NPR1 (NONEXPRESSOR of PATHOGENESIS-RELATED GENES 1) functions as the central coactivator of TGA transcription factors. Recently, two alternative but not exclusive models for SA perception mechanisms were proposed. The first model is that NPR1 homologs, NPR3 and NPR4, perceive SA thereby regulating NPR1 protein accumulation. The second model describes that NPR1 itself perceives SA, triggering an NPR1 conformational change thereby activating SA-mediated transcription. Besides the direct SA binding, NPR1 is also regulated by SA-mediated redox changes and phosphorylation. Emerging evidence show that pathogen virulence effectors target SA signaling, further strengthening the importance of SA-mediated immunity.

Keywords: calcium, ICS1, NPR1, plant immunity, salicylic acid, SA perception, transcriptional reprogramming

\section{INTRODUCTION}

The phytohormone salicylic acid (SA) is a small phenolic compound that functions as an important signaling molecule during plant immunity (Vlot et al., 2009; Robert-Seilaniantz et al., 2011; Pieterse et al., 2012). Since constitutive SA accumulation is often associated with stunted plant growth, resulting in reduction of plant fitness (Ishihara et al., 2008; Pajerowska-Mukhtar et al., 2012; Chandran et al., 2014), SA biosynthesis and SA-mediated signaling are tightly controlled.

The plant immune system comprises multiple layers, such as pattern-triggered immunity (PTI) and effector-triggered immunity (ETI; Jones and Dangl, 2006; Tsuda and Katagiri, 2010). PTI is triggered by recognition of common microbial components (MAMPs, microbe-associated molecular patterns), such as bacterial flagellin or the fungal cell wall component chitin (Boller and Felix, 2009; Macho and Zipfel, 2014). MAMP recognition stimulates generation of reactive oxygen species, intracellular calcium influx, transient activation of mitogen-activated protein kinases (MAPKs), and the production of SA (Tsuda et al., 2008a,b; Tsuda and Katagiri, 2010). Virulent pathogens, for example, the bacterial pathogen Pseudomonas syringae pv. tomato DC3000 (Pto DC3000), however, can suppress PTI in Arabidopsis and tomato by effectors, injected via bacterial secretion systems into the plant cell (Lohou et al., 2013; Xin and He, 2013). Recent studies identified various effectors that interfere with SA signaling (Uppalapati et al., 2007; Djamei et al., 2011; Caillaud et al., 2013; Jiang et al., 2013; Rabe et al., 2013; Gimenez-Ibanez et al., 2014; Liu et al., 2014), highlighting the importance of SA signaling for plant immunity. To regain resistance, plants have acquired intracellular receptors [resistance $(\mathrm{R})$ proteins], which induce the second layer of defense after effector recognition, termed ETI (Eitas and Dangl, 2010; Bonardi and Dangl, 2012; Jacob et al., 2013). Activation of ETI also induces SA accumulation and MAPK activation, which are also important for resistance against pathogens during ETI (Tsuda et al., 2013). Additionally, SA has vital roles in establishing systemic acquired resistance (SAR), a form of long-term and broad-spectrum resistance throughout the entire plant after local pathogen infection (Wang et al., 2006; Fu and Dong, 2013).

In this review, we summarize SA signal transduction from regulation of biosynthesis, perception, to transcriptional reprogramming during plant immunity. We also discuss compensation mechanisms that would provide robust immunity once SA signaling is compromised, for example, by pathogen effector attack. SA signaling pathway is highly interconnected with other phytohormone signaling such as mediated by jasmonates (JA), ethylene, and abscisic acid (Robert-Seilaniantz et al., 2011; Pieterse et al., 2012; Derksen et al., 2013). For example, JA and ethylene signaling negatively regulate SA biosynthesis at the transcriptional level (Chen et al., 2009; Zheng et al., 2012). However, discussions on these are beyond the scope of this review. 


\section{THE BIOSYNTHESIS OF SA IN PLANTS BIOSYNTHETIC PATHWAYS}

Two major SA biosynthetic pathways in plants were identified: the isochorismate (IC) and the phenylalanine ammonia-lyase (PAL) pathways. Both pathways commonly utilize chorismate, the end product of the shikimate pathway, to produce SA (Dempsey et al., 2011). IC synthase (ICS) and PAL are critical enzymes for these pathways, respectively. Homologs of ICS and PAL genes are present throughout the plant kingdom, including Arabidopsis, tobacco, tomato, populus, sunflower, and pepper (Wildermuth et al., 2001; Cochrane et al., 2004; Uppalapati et al., 2007; Catinot et al., 2008; Yuan et al., 2009; Sadeghi et al., 2013; Kim and Hwang, 2014), suggesting the importance of these SA biosynthesis pathways to survive during the course of evolution. In Arabidopsis, mutations in ICS1 lead to an almost complete loss of pathogeninduced SA accumulation (Wildermuth et al., 2001). However, Arabidopsis quadruple PAL mutants, in which PAL activity is reduced to $10 \%$, also show lower SA accumulation (50\%) compared to the wild type upon pathogen infection (Huang et al., 2010). Thus, while contribution of the PAL pathway is evident, the IC pathway is the major route for SA biosynthesis during plant immunity.

In chloroplasts, ICS catalyzes the conversion of chorismate into IC (Wildermuth et al., 2001; Strawn et al., 2007; Garcion et al., 2008), which is further converted to SA (Dempsey et al., 2011). In some bacteria, conversion of IC to SA is catalyzed by IC pyruvate lyases (IPLs; Dempsey et al., 2011). However, plant genomes encode no homologous genes to bacterial IPLs. Expression of bacterial enzymes catalyzing this conversion together with ICS in chloroplasts leads to constitutive accumulation of SA (Verberne et al., 2000; Mauch et al., 2001). Thus, it is conceivable that plants have yet-determined gene(s) whose product(s) possess IPL activity in chloroplasts. However, metabolic enzymes such as the acyl acid amido synthetase GH3.12 [also known as PBS3/WIN3/GDG1 (AVRPPHB SUSCEPTIBLE 3/HOPW1INTERACTING 3/GH3-LIKE DEFENSE GENE 1); Nobuta et al., 2007; Zhang et al., 2007; Okrent et al., 2009; Westfall et al., 2010, 2012] and the acyltransferase EPS1 (ENHANCED PSEUDOMONAS SUSCEPTIBILITY 1; Zheng et al., 2009) are involved in SA accumulation, perhaps by providing SA precursors or regulatory molecules for SA biosynthesis. Thus, SA biosynthesis may be more complex in plants compared to bacteria. SA export from chloroplasts is mediated by the MATE-transporter EDS5 (ENHANCED DISEASE SUSCEPTIBILITY 5; Serrano et al., 2013). This export seems important for SA accumulation and distribution in the cell since SA accumulation is compromised in eds5 mutants (Nawrath et al., 2002; Ishihara et al., 2008).

\section{REGULATION OF SA BIOSYNTHESIS}

Salicylic acid biosynthesis is tightly regulated since constitutive SA accumulation has negative impacts on plant fitness (Ishihara et al., 2008; Pajerowska-Mukhtar et al., 2012; Chandran et al., 2014). Accumulating evidence show that transcriptional control of ICS1 by calcium signaling is key for the initiation of SA biosynthesis (Figure 1). The concentration of calcium ions $\left(\mathrm{Ca}^{2+}\right)$ in the cytosol transiently increases upon immune receptor activation through $\mathrm{Ca}^{2+}$ channels. Elevation of intracellular $\mathrm{Ca}^{2+}$, called
$\mathrm{Ca}^{2+}$ signature, is decoded by $\mathrm{Ca}^{2+}$ sensor proteins, such as calmodulin $(\mathrm{CaM})$ and $\mathrm{Ca}^{2+}$-dependent protein kinases (CDPKs; Dodd et al., 2010; Boudsocq and Sheen, 2013; Poovaiah et al., 2013; Schulz et al., 2013). Binding of CaM regulates target protein activities thereby relaying $\mathrm{Ca}^{2+}$ signatures to downstream responses. During Arabidopsis immunity, the CaM-binding transcription factor CBP60g (CALMODULIN BINDING PROTEIN $60 \mathrm{~g}$ ) and its homolog SARD1 (SYSTEMIC ACQUIRED RESISTANCE DEFICIENT 1) control ICS1 transcription (Wang et al., 2009, 2011; Zhang et al., 2010; Wan et al., 2012). CaM-binding is required for CBP60g function, whereas SARD1 does not appear to be a CaM-binding protein (Wang et al., 2009). Despite this difference, CBP60g and SARD1 are partially redundant for ICS1 expression and SA accumulation during immunity. However, dual regulation of ICS1 transcription by CBP60g and SARD1 seems important for temporal dynamics of SA biosynthesis: CBP60g mainly contributes to SA biosynthesis at early stages after $P$. syringae infection while SARD1 does at late stages (Wang et al., 2011). Another close homolog of CBP60g, CBP60a, negatively regulates ICS1 expression upon CaM-binding (Truman et al., 2013). Conceivably, upon pathogen attack, CBP60g and SARD1 bind to the ICS1 promoter and activate its expression, at least partly by removing the negative regulator CBP60a from the ICS1 promoter.

Unlike CaM, CDPKs have both intrinsic $\mathrm{Ca}^{2+}$ sensing and responding sites thereby allowing individual CDPK proteins to relay $\mathrm{Ca}^{2+}$ signatures to downstream components via phosphorylation events. Recently, the CDPKs, CPK4, 5, 6, and 11, were shown to re-localize to the nucleus, and to interact with and phosphorylate the WRKY transcription factors, WRKY8, 28, and 48, during ETI mediated by the plasma membrane-associated immune receptors RPS2 (RESISTANCE TO P.SYRINGAE 2) or RPM1 (RESISTANCE TO P.SYRINGAE PV MACULICULA 1; Gao et al., 2013). Mutants in WRKY8 or WRKY48 are compromised in pathogen-induced ICS1 expression. Furthermore, WRKY28 directly interacts with the ICS1 promoter (van Verk et al., 2011), which might be regulated through phosphorylation by CPK4, 5, 6, or 11 . Collectively, these results suggest that during ETI, these CDPKs relay $\mathrm{Ca}^{2+}$ signatures to activate ICS1 transcription via WRKY transcription factors.

Besides ICS1 regulation, calcium signaling also affects the maintenance of SA accumulation through transcriptional regulation of EDS1 (ENHANCED DISEASE SUSCEPTIBILITY 1; Du et al., 2009), encoding a central regulator of the positive feedback loop of SA accumulation (Feys et al., 2001). A CaM-binding transcription factor, CAMTA3/SR1 (CALMODULIN BINDING TRANSCRIPTION ACTIVATOR 3/SIGNALRESPONSIVE GENE 1), binds to the EDS1 promoter to repress its transcription, and mutants of CAMTA3/SR1 show elevated SA levels and enhanced immunity against $P$. syringae and the fungal pathogen Botrytis cinerea. Combinatorial mutant analysis indicates that CAMTA3/SR1 and its homologs CAMTA1/2 also suppress expression of CBP60g, SARD1, and ICS1 (Kim et al., 2013). Thus, the three CAMTA homologs coordinately suppress SA accumulation, but it remains unknown if the CAMTA transcription factors directly target the promoters of CBP60g, SARD1, and ICS1. It was recently shown 


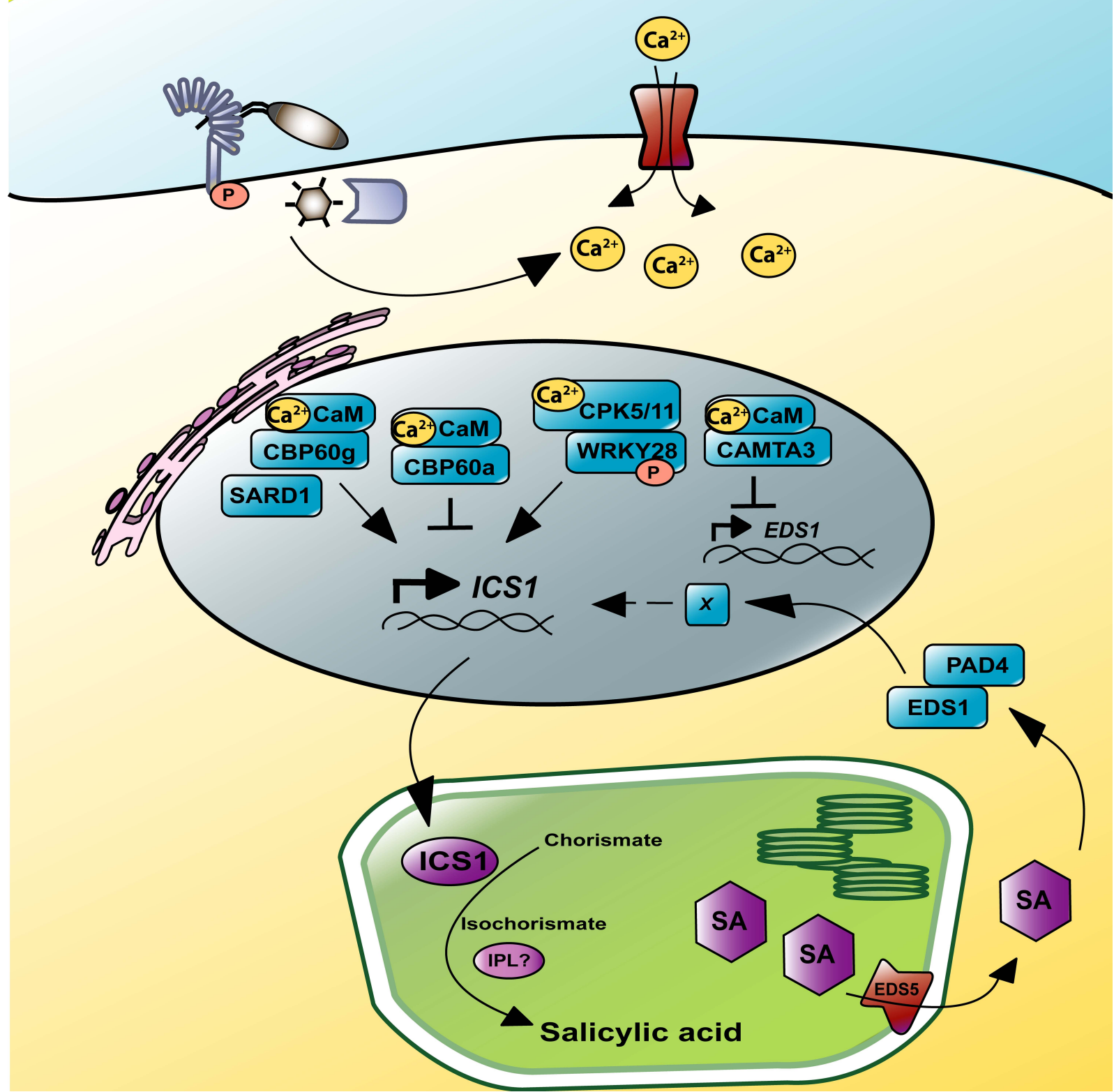

FIGURE 1 | Regulation of SA accumulation by calcium signaling. MAMP or effector recognition increases intracellular $\mathrm{Ca}^{2+}$ concentrations thereby regulating calcium sensor proteins, such as $\mathrm{CaM}$ and CDPKs. The CaM-binding transcription factors CBP60g and CBP60a are positive and negative regulators of ICS1 transcription, respectively. A homolog of CBP60a/g, SARD1, is not a CaM-binding protein but functions redundantly with CBP60g for ICS1 transcription. WRKY28, whose DNA-binding activity is regulated by the CDPKs CPK5 and CPK11, also contributes to ICS1 expression. ICS1 mediates SA production in chloroplasts, by conversion of chorismate into the SA-precursor isochorismate. SA may be transported through the MATE-transporter EDS5 into the cytosol. The EDS1/PAD4 complex contributes to the positive feedback loop of SA accumulation. Repression of EDS1 transcription by the $\mathrm{Ca}^{2+} / \mathrm{CaM}$-binding transcription factor CAMTA3 represents a fine-tuning mechanism for SA accumulation. that a CAMTA3/SR1-interacting protein links CAMTA3/SR1 to ubiquitin-mediated protein degradation thereby enhancing EDS1 expression and immunity against $P$. syringae (Zhang et al., 2014).

In summary, these results clearly indicate the importance of $\mathrm{Ca}^{2+}$ signaling in regulation of SA accumulation during immunity through transcriptional regulation of genes involved in SA biosynthesis and maintenance. However, how plants spatiotemporally coordinate positive and negative regulators of SA biosynthesis and accumulation remains to be investigated.

\section{SA PERCEPTION}

Identification of SA receptor(s) has been one of the major research interests for the last two decades. Considering its diverse functions in environmental stress response, plants may have multiple SA receptors. Indeed, biochemical approaches identified a num- 
ber of SA-interacting proteins, and activities of these proteins were affected by SA-binding (Chen and Klessig, 1991; Chen et al., 1993; Durner and Klessig, 1995; Du and Klessig, 1997; Slaymaker et al., 2002; Kumar and Klessig, 2003; Forouhar et al., 2005; Park et al., 2009; Tripathi et al., 2010; Tian et al., 2012; Moreau et al., 2013). However, these SA-binding proteins do not fully explain SA response including SA-mediated transcriptional reprogramming. Recently, the three NPR (NON-EXPRESSOR of PATHOGENESIS-RELATED GENES) family members, NPR1, NPR3, and NPR4, were identified as bona fide SA receptors in Arabidopsis (Fu et al., 2012; Wu et al., 2012). In this section, we discuss how these NPR proteins function as SA receptors.

NPR1 is a master regulator of SA-mediated transcriptional reprogramming and immunity, functioning as a transcriptional coactivator (Pajerowska-Mukhtar et al., 2013). NPR1 comprises a BTB/POZ (broad-complex, tramtrack, and bric-à-brac/poxvirus and zinc-finger) domain, an ankyrin repeat domain, and a nuclear localization sequence. Mutations in NPR1 lead to an almost complete loss of SA-mediated transcriptional reprogramming and great susceptibility to (hemi)-biotrophic pathogens (Shah et al., 1997; Volko et al., 1998; Dong, 2004). Therefore, it was not surprising but sensational that Wu et al. (2012) found NPR1 to be a bona fide SA receptor (Figure 2A). Using an equilibrium method, they showed that Arabidopsis NPR1 directly binds SA $(\mathrm{Kd}=140 \mathrm{nM})$, but not inactive structural analogs, through Cys ${ }^{521 / 529}$ via the transition metal copper. Consistently, Cys $^{521 / 529}$ were previously identified as key amino acid residues for Arabidopsis NPR1 function (Rochon et al., 2006). Biochemical approaches indicate that SA-binding triggers a conformational change in NPR1. Further protein deletion analyses suggest that the C-terminal transactivation domain of NPR1 is intramolecularly inhibited by the N-terminal BTB/POZ domain and that SA-binding releases the transactivation domain from $\mathrm{BTB} / \mathrm{POZ}$ suppression. Thus, the study established a model with NPR1 as an SA receptor that also functions as a master signal transducer of SA signaling. However, Cys ${ }^{521 / 529}$ are not conserved among

A

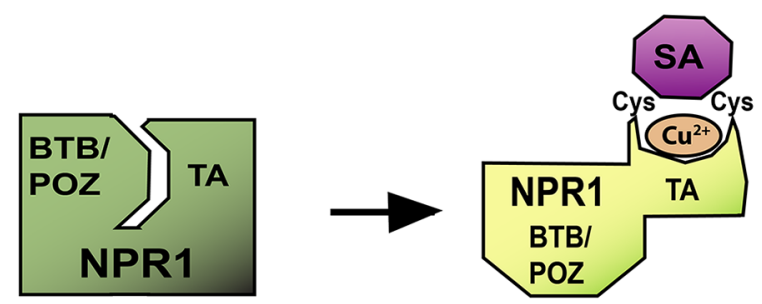

B

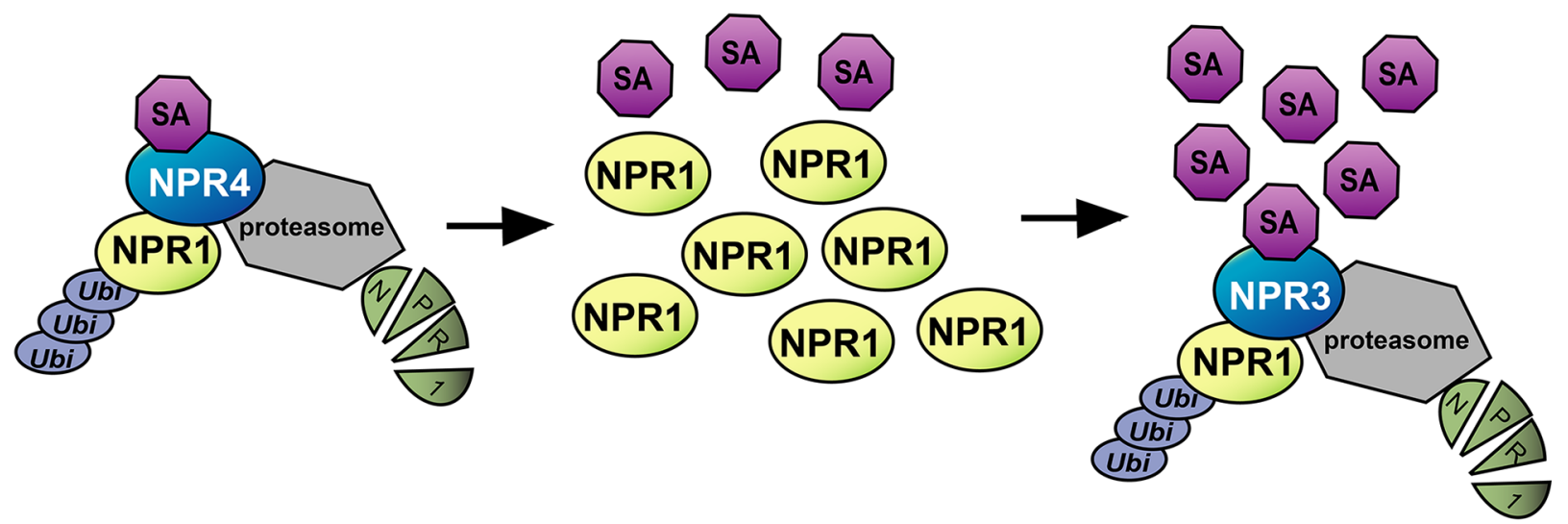

SA concentration

FIGURE 2 | Models for SA perception. (A) Direct SA binding to NPR1 modulates its activity. In unstressed conditions, the C-terminal transactivation domain of NPR1 is repressed by the N-terminal BTB/POZ domain, keeping NPR1 in an inactive state (green). NPR1 perceives SA through $C y s^{521 / 529}$ via the transition metal copper, which triggers a conformation change of NPR1, resulting in de-repression of the transactivation domain and activation of NPR1 (yellow). (B) NPR1 accumulation is regulated by SA through the SA receptors NPR3 and NPR4. Pathogen infection triggers SA accumulation. In the case of low SA, the SA-receptor NPR4 triggers NPR1 degradation through the 26S proteasome. When SA levels are intermediate, NPR1 protein accumulates. High SA-concentrations trigger the SA receptor NPR3-mediated NPR1 degradation. Thus, only intermediate levels of SA achieve NPR1 accumulation thereby activating SA-mediated transcriptional reprogramming. 
plant species, raising an issue of the evolutionary significance of the SA perception mechanism via NPR1. In addition, another study showed that NPR1 does not bind SA in a conventional nonequilibrium ${ }^{3} \mathrm{H}$-SA binding assay (Yan and Dong, 2014). Instead, Fu et al. (2012) identified two homologs of NPR1, NPR3 and NPR4, as SA receptors (Figure 2B; Fu et al., 2012). NPR1 is subject to degradation via the $26 \mathrm{~S}$ proteasome pathway in the absence of SA (Spoel et al., 2009). Once SA increases upon pathogen infection, NPR1 is stabilized. However, full induction of SA-responsive genes also requires NPR1 turnover. Thus, regulation of NPR1 protein level is critical for SA response. Fu et al. (2012) found that NPR3 and NPR4 interact with NPR1 and are required for NPR1 degradation (Fu et al., 2012). NPR4 has a high SA affinity $(\mathrm{Kd}=46 \mathrm{nM})$ whereas NPR3 shows a low affinity $(\mathrm{Kd}=981 \mathrm{nM})$, suggesting differential regulations of NPR1 by NPR3 and NPR4. Interestingly, SA disrupts NPR1-NPR4 interaction, but facilitates NPR1-NPR3 interaction. These observations support a model in which NPR3 and NPR4 create an NPR1 protein concentration gradient in order to regulate NPR1-mediated transcription: in the absence of SA, NPR4-mediated NPR1 degradation prevents NPR1 accumulation whereas high SA levels also prevent NPR1 accumulation due to NPR3. Thus, NPR1-mediated signaling is active only at intermediate SA levels. This model is consistent with the observation that NPR1 protein highly accumulates at sites surrounding the infection site in a leaf. These regions are supposed to contain intermediate SA levels, while the infection site may have too high SA levels. Although this model is attractive, further validation is required.

Collectively, two alternative but not exclusive SA perception mechanisms in plant cells were identified, but further research is still required to address fundamental questions. For example, the subcellular location(s) of SA perception have not been addressed yet. The nuclear NPR1 pool is necessary for SA-mediated transcription (Mou et al., 2003). Consistently, NPR3 and NPR4 are nuclear proteins, and therefore SA is likely perceived by them in the nucleus to regulate nuclear NPR1 amount. On the other hand, the cytosolic NPR1 pool may regulate cross-talk between SA- and JA-mediated transcriptional reprogramming (Spoel et al., 2003), suggesting that SA is also perceived in the cytosol. Since SA perception by nuclear NPR3 and NPR4 does not explain this observation, cytosolic NPR1 activity may be regulated by the direct SA binding.

\section{SA-MEDIATED TRANSCRIPTIONAL REPROGRAMMING}

NPR1 controls expression of more than 95\% of the responsive genes to the SA-analog benzothiadiazole (BTH; Wang et al., 2006). Functional regulation of NPR1 is not only mediated by the direct SA binding, but also by SA-triggered redox changes (Mou et al., 2003). In the absence of SA, NPR1 is present as an oligomer formed through intermolecular disulfide bonds. SA triggers changes in the cellular redox potential, thereby reducing cysteine residues in NPR1 through the thioredoxins TRXh3 and TRXh5, resulting in monomerization of NPR1 (Tada et al., 2008). Mutations in the cysteine residues $\left(\mathrm{Cys}^{82}\right.$ or $\mathrm{Cys}^{216}$ ) lead to constitutive monomerization and nuclear accumulation of NPR1, resulting in activation of PR1 expression (Mou et al., 2003). Nuclear accumulation of NPR1 triggered by SA can be explained by stabilization of nuclear NPR1 or translocation of the NPR1 monomer from the cytosol to the nucleus. Thus, SA-triggered NPR1 monomerization and nuclear accumulation are important steps for NPR1-mediated transcription. However, forced nuclear localization of NPR1 is not sufficient for transcriptional reprogramming, as the presence of SA is additionally required for full PR1 induction (Kinkema et al., 2000; Spoel et al., 2003). This can be explained by the observation that SA-binding triggers the NPR1 conformational change thereby allowing NPR1 to regulate gene expression (Wu et al., 2012). Additional regulation of NPR1 involves phosphorylation (Spoel et al., 2009). SA triggers phosphorylation of NPR1 at the N-terminus $\left(\operatorname{Ser}^{11 / 15}\right)$ in the nucleus via yet-determined kinase(s). NPR1 phosphorylation contributes to its recruitment to a ubiquitin ligase, resulting in proteasomemediated NPR1 degradation. This degradation is required for the proper transcriptional control by NPR1, perhaps by allowing fresh NPR1 to reinitiate the next cycle of transcription.

NPR1 regulates transcription of SA-responsive genes through interactions with specific transcription factors (Figure 3). Identified major transcription factors belong to a subclass of the basic leucine zipper transcription factor family, TGA (Gatz, 2013). The Arabidopsis genome encodes 10 TGA transcription factors, which are structurally divided into five subgroups and all bind the consensus DNA sequence TGACG. Yeast-two-hybrid analyses with NPR1 and TGA transcription factors show interaction specificity for clade II TGAs (TGA2/TGA5/TGA6) and TGA3 (clade III; Zhou et al., 2000; Hepworth et al., 2005). Genetic analysis reveal that TGA2, TGA5, and TGA6 repress $P R 1$ transcription in the absence of SA, but on the other hand are required for

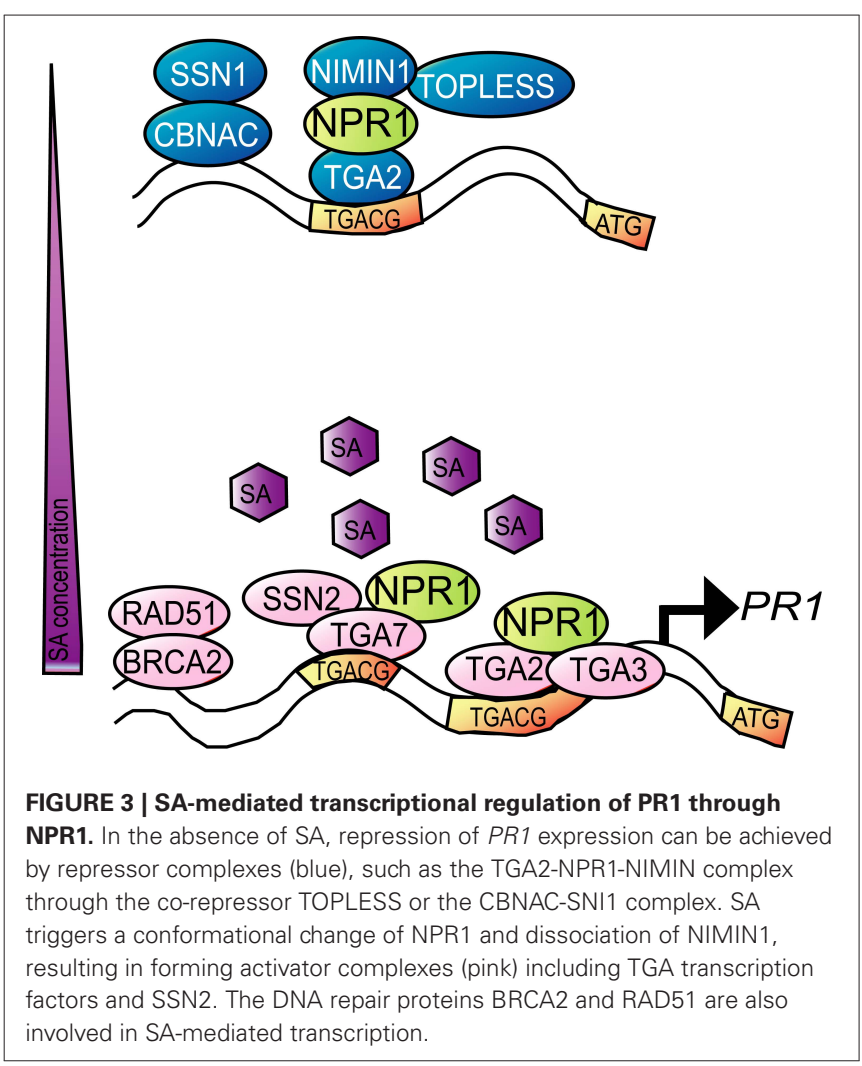


PR1 induction in the presence of SA (Zhang et al., 2003). In the absence of SA, TGA2 binds to the $P R 1$ promoter thereby repressing its transcription (Rochon et al., 2006; Boyle et al., 2009). An NPR1-interacting protein, NIMIN1 (NPR1/NIM1INTERACTING PROTEIN 1), can form a ternary complex with TGA2 through NPR1 at least in yeast (Weigel et al., 2005). Transcriptional repression by TGA2 may be achieved through NIMIN1 interacting with a transcriptional co-repressor, TOPLESS (Braun et al., 2011). Conceivably, SA allows NPR1 to form a different complex with TGA2 and other TGA factors, such as TGA3 thereby activating PR1 transcription (Johnson et al., 2003). The NIMIN1NPR1-TGA2 complex is dissociated in the presence of SA in yeast (Hermann et al., 2013). Thus, NIMIN1 dissociation from the NPR1-TGA transcriptional complex by SA may contribute to activation of the NPR1-TGA transcriptional complex. This transcriptional activation may be relayed through specific mediator subunits, such as the Mediator subunit MED15, since med15 mutants are insensitive to SA (Canet et al., 2012).

A suppressor screen of nprl identified SNI1 (SUPPRESSOR OF NPR1 INDUCIBLE 1) as another repressor of SA-responsive genes (e.g., PR1) in unstressed conditions (Li et al., 1999; Mosher et al., 2006). SNI1-mediated transcriptional repression may be achieved through the CaM-binding NAC (NAM, ATAF1,2, CUC2) transcription repressor CBNAC, since SNI1 directly interacts with CBNAC and enhances CBNAC-binding activity to the PR1 promoter (Kim et al., 2012). Upon SA treatment, SNI1 is dissociated from the $P R 1$ promoter and replaced by the DNA repair protein SSN2 (Song et al., 2011). Although SSN2 contains a DNAbinding domain, its binding to the PR1 promoter requires NPR1 and the transcription factor TGA7. These results suggest that SA triggers NPR1 activation through nuclear accumulation and conformational change, resulting in the formation of a TGA7NPR1-SSN2 complex that activates $P R 1$ transcription. Additional DNA repair proteins, such as BRCA2A (BREAST CANCER 2A) and RAD51D, are also functionally associated with SA-mediated transcription (Durrant et al., 2007; Wang et al., 2010; Song et al., 2011). Interestingly, SA and Pseudomonas infection cause DNA damage, such as DNA double strand breaks, suggesting that DNA damage response is an intrinsic component of SA-mediated transcription during plant immunity (Yan et al., 2013; Song and Bent, 2014).

Besides functional regulation of transcription factors by NPR1 through complex formation, NPR1 also controls expression of transcription factors, such as WRKY transcription factors, which are required for SA-mediated transcriptional reprogramming (Wang et al., 2006; Pajerowska-Mukhtar et al., 2012). The Arabidopsis genome encodes 74 WRKY factors which bind the specific DNA sequence (C/TTGACT/C), termed the W-box (Rushton et al., 2010). WRKY factors form a complex interconnected regulatory network, containing recurring regulatory patterns, such as both positive and negative feedback and feedforward loops. This WRKY network ensures rapid and efficient signal amplification and allows tight control to limit the plant immune response. Furthermore, the presence of multiple W-boxes in the NPR1 promoter suggests regulation of NPR1 expression by WRKY factors, which is indeed supported by NPR1 promoter analysis (Yu et al., 2001). Thus, WRKY transcriptional regulatory networks downstream of NPR1 amplify and fine-tune SA-mediated transcriptional reprogramming.

\section{COMPENSATION OF SA SIGNALING}

The importance of SA signaling during immunity is reflected by the fact that pathogen effectors target it for virulence, either by preventing SA accumulation (Djamei et al., 2011; Rabe et al., 2013; Liu et al., 2014) or by dampen SA signaling and transcriptional regulation, using the antagonistic interaction between SA and JA signaling (Uppalapati et al., 2007; Caillaud et al., 2013; Jiang et al., 2013; Gimenez-Ibanez et al., 2014). It is reasonable to assume that plants have evolved compensatory mechanism(s) to circumvent weakened SA signaling upon effector attack, thereby ensuring robust immune response (Tsuda and Katagiri, 2010). For example, although it is believed that SA and JA signaling antagonize each other, a recent study suggests the compensation of SA accumulation by JA (Kim et al., 2014). The MAMP flg22 induces SA accumulation in an ICS1-dependent manner (Tsuda et al., 2008b). Additionally, a component of the SA amplification loop, PAD4, is required for full induction of SA (Zhou et al., 1998; Tsuda et al., 2008b). In agreement with the antagonistic relationship between JA and SA, single mutation in the JA biosynthesis gene DDE2 leads to higher SA accumulation upon flg22 treatment. However, combined mutation in DDE2 and PAD4 diminishes SA accumulation comparable to that in sid2, suggesting that although JA suppresses SA accumulation through PAD4, it also supports SA accumulation once PAD4 is compromised. Thus, JA signaling represents a compensation mechanism for SA accumulation during PTI.

In addition to JA, MAPK signaling also compensates SA signaling to secure transcriptional regulation of SA-responsive genes in ETI (Tsuda et al., 2013). Activation of the Arabidopsis MAPKs MPK3 and MPK6 is transient during PTI, but sustained during RPS2- and RPM1-mediated ETI (Tsuda et al., 2013), or upon B. cinerea infection (Han et al., 2010). While transient activation of MPK3 and MPK6 is not sufficient to overcome SA-dependency of a subset of SA-responsive genes such as $P R 1$, prolonged activation of MPK3 and MPK6 facilitates their transcriptional regulation independent of SA. Furthermore, this compensation mechanism does not require NPR1 since NPR1 mutation does not affect PR1 induction mediated by prolonged MAPK activation. It can be assumed that prolonged MAPK activation bypasses the requirement of NPR1 to regulate transcription factor(s) involved in SA response. Although transcription factors shared by SA and the MAPK cascade are not known, large-scale protein target identifications of MPK3 and MPK6 would help to identify candidates (Popescu et al., 2009; Hoehenwarter et al., 2013). Among them, TGA transcription factors are reasonable candidates (Wang and Fobert, 2013). However, how this quantitative MAPK activation leads to qualitatively different transcriptional outputs still remains to be determined. One possible answer lays in temporal regulation of transcription factor(s). Hereby, the MAPKs first activate expression of transcription factor(s), and later on phosphorylate the accumulated transcription factor(s), representing a feedforward loop for activation of the transcription factor(s). In this case, only prolonged MAPK activation ensures activation of the transcription factor(s). Indeed, the MAPKs regulate expression of 
a diverse transcription factor set (Mao et al., 2011; Li et al., 2012; Meng et al., 2013; Tsuda et al., 2013; Frei dit Frey et al., 2014), but whether the MAPKs also phosphorylate them is a future issue.

\section{CONCLUSIONS AND PERSPECTIVES}

Over the past decade a number of researches have shed light into our understanding of SA-mediated signaling, through the discoveries of calcium signaling as the major switch for SA biosynthesis, NPR family members as SA receptors, and the mechanism for NPR1-mediated transcriptional reprogramming. However, many questions are still unanswered, starting with identification of plant IPL gene(s) to further validate the IC pathway as the major route for SA biosynthesis in plants. The controversy for SA perception should also be solved in the future. In addition, information for temporal and spatial dynamics of SA biosynthesis and SA-mediated transcriptional reprogramming is missing. For this, systems approaches using time-series genomics data sets and tissue-specific analysis will help our conception (Mine et al., 2014). Most studies are based on experiments using the model plant Arabidopsis. Analysis of different plant species is necessary to understand evolutionary conservation and diversification of SA signal transduction. Finally, identification of the molecular components in MAPK-mediated SA/NPR1-independent gene regulation of SA-responsive genes in ETI will shed light on the molecular mechanism of SA compensation.

\section{ACKNOWLEDGMENTS}

We thank Akira Mine, Shajahan Anver, and Sajjad Khani for critical reading of the manuscript. This work was supported by the Max Planck Society (Carolin Seyfferth, Kenichi Tsuda) and a grant from the German Research Council SFB670 (Kenichi Tsuda).

\section{REFERENCES}

Boller, T., and Felix, G. (2009). A renaissance of elicitors: perception of microbeassociated molecular patterns and danger signals by pattern-recognition receptors. Annu. Rev. Plant Biol. 60, 379-406. doi: 10.1146/annurev.arplant.57. 032905.105346

Bonardi, V., and Dangl, J. L. (2012). How complex are intracellular immune receptor signaling complexes? Front. Plant Sci. 3:237. doi: 10.3389/fpls.2012.00237

Boudsocq, M., and Sheen, J. (2013). CDPKs in immune and stress signaling. Trends Plant Sci. 18, 30-40. doi: 10.1016/j.tplants.2012.08.008

Boyle, P., Le Su, E., Rochon, A., Shearer, H. L., Murmu, J., Chu, J. Y., et al. (2009). The BTB/POZ domain of the Arabidopsis disease resistance protein NPR1 interacts with the repression domain of TGA2 to negate its function. Plant Cell 21, 3700-3713. doi: 10.1105/tpc.109.069971

Braun, P., Carvunis, A. R., Charloteaux, B., Dreze, M., Ecker, J. R., Hill, D. E., et al. (2011). Evidence for network evolution in an Arabidopsis interactome map. Science 333, 601-607. doi: 10.1126/science.1203877

Caillaud, M. C., Asai, S., Rallapalli, G., Piquerez, S., Fabro, G., and Jones, J. D. (2013). A downy mildew effector attenuates salicylic acid-triggered immunity in Arabidopsis by interacting with the host mediator complex. PLoS Biol. 11:e1001732. doi: 10.1371/journal.pbio.1001732

Canet, J. V., Dobon, A., and Tornero, P. (2012). Non-recognition-of-BTH4, an Arabidopsis mediator subunit homolog, is necessary for development and response to salicylic acid. Plant Cell 24, 4220-4235. doi: 10.1105/tpc.112.103028

Catinot, J., Buchala, A., Abou-Mansour, E., and Metraux, J. P. (2008). Salicylic acid production in response to biotic and abiotic stress depends on isochorismate in Nicotiana benthamiana. FEBS Lett. 582, 473-478. doi: 10.1016/j.febslet.2007.12.039

Chandran, D., Rickert, J., Huang, Y., Steinwand, M. A., Marr, S. K., and Wildermuth, M. C. (2014). Atypical E2F transcriptional repressor DEL1 acts at the intersection of plant growth and immunity by controlling the hormone salicylic acid. Cell Host Microbe 15, 506-513. doi: 10.1016/j.chom.2014.03.007

Chen, H., Xue, L., Chintamanani, S., Germain, H., Lin, H., Cui, H., et al. (2009). ETHYLENE INSENSITIVE3 and ETHYLENE INSENSITIVE3-LIKE1 repress SALICYLIC ACID INDUCTION DEFICIENT2 expression to negatively regulate plant innate immunity in Arabidopsis. Plant Cell 21, 2527-2540. doi: 10.1105/tpc.108.065193

Chen, Z., and Klessig, D. F. (1991). Identification of a soluble salicylic acidbinding protein that may function in signal transduction in the plant disease-resistance response. Proc. Natl. Acad. Sci. U.S.A. 88, 8179-8183. doi: 10.1073/pnas.88.18.8179

Chen, Z., Silva, H., and Klessig, D. F. (1993). Active oxygen species in the induction of plant systemic acquired resistance by salicylic acid. Science 262, 1883-1886. doi: $10.1126 /$ science. 8266079

Cochrane, F. C., Davin, L. B., and Lewis, N. G. (2004). The Arabidopsis phenylalanine ammonia lyase gene family: kinetic characterization of the four PAL isoforms. Phytochemistry 65, 1557-1564. doi: 10.1016/j.phytochem.2004.05.006

Dempsey, D. A., Vlot, A. C., Wildermuth, M. C., and Klessig, D. F. (2011). Salicylic Acid biosynthesis and metabolism. Arabidopsis Book 9, e0156. doi: 10.1199/tab.0156

Derksen, H., Rampitsch, C., and Daayf, F. (2013). Signaling cross-talk in plant disease resistance. Plant Sci. 207, 79-87. doi: 10.1016/j.plantsci.2013.03.004

Djamei, A., Schipper, K., Rabe, F., Ghosh, A., Vincon, V., Kahnt, J., et al. (2011). Metabolic priming by a secreted fungal effector. Nature 478, 395-398. doi: 10.1038 /nature10454

Dodd, A. N., Kudla, J., and Sanders, D. (2010). The language of calcium signaling. Annu. Rev. Plant Biol. 61, 593-620. doi: 10.1146/annurev-arplant-070109104628

Dong, X. (2004). NPR1, all things considered. Curr. Opin. Plant Biol. 7, 547-552. doi: 10.1016/j.pbi.2004.07.005

Du, H., and Klessig, D. F. (1997). Identification of a soluble, high-affinity salicylic acid-binding protein in tobacco. Plant Physiol. 113, 1319-1327.

Du, L., Ali, G. S., Simons, K. A., Hou, J., Yang, T., Reddy, A. S., et al. (2009). $\mathrm{Ca}^{2+} /$ calmodulin regulates salicylic-acid-mediated plant immunity. Nature 457, 1154-1158. doi: 10.1038/nature07612

Durner, J., and Klessig, D. F. (1995). Inhibition of ascorbate peroxidase by salicylic acid and 2,6-dichloroisonicotinic acid, two inducers of plant defense responses. Proc. Natl. Acad. Sci. U.S.A. 92, 11312-11316. doi: 10.1073/pnas.92.24.11312

Durrant, W. E., Wang, S., and Dong, X. (2007). Arabidopsis SNI1 and RAD51D regulate both gene transcription and DNA recombination during the defense response. Proc. Natl. Acad. Sci. U.S.A. 104, 4223-4227. doi: 10.1073/pnas.0609357104

Eitas, T. K., and Dangl, J. L. (2010). NB-LRR proteins: pairs, pieces, perception, partners, and pathways. Curr. Opin. Plant Biol. 13, 472-477. doi: 10.1016/j.pbi.2010.04.007

Feys, B. J., Moisan, L. J., Newman, M. A., and Parker, J. E. (2001). Direct interaction between the Arabidopsis disease resistance signaling proteins, EDS1 and PAD4. EMBO J. 20, 5400-5411. doi: 10.1093/emboj/20.19.5400

Forouhar, F., Yang, Y., Kumar, D., Chen, Y., Fridman, E., Park, S. W., et al. (2005). Structural and biochemical studies identify tobacco SABP2 as a methyl salicylate esterase and implicate it in plant innate immunity. Proc. Natl. Acad. Sci. U.S.A. 102, 1773-1778. doi: 10.1073/pnas.0409227102

Frei dit Frey, N., Garcia, A. V., Bigeard, J., Zaag, R., Bueso, E., Garmier, M., et al. (2014). Functional analysis of Arabidopsis immune-related MAPKs uncovers a role for MPK3 as negative regulator of inducible defences. Genome Biol. 15, R87. doi: 10.1186/gb-2014-15-6-r87

Fu, Z. Q., and Dong, X. (2013). Systemic acquired resistance: turning local infection into global defense. Annu. Rev. Plant Biol. 64, 839-863. doi: 10.1146/annurevarplant-042811-105606

Fu, Z. Q., Yan, S., Saleh, A., Wang, W., Ruble, J., Oka, N., et al. (2012). NPR3 and NPR4 are receptors for the immune signal salicylic acid in plants. Nature 486, 228-232. doi: 10.1038/nature11162

Gao, X., Chen, X., Lin, W., Chen, S., Lu, D., Niu, Y., et al. (2013). Bifurcation of Arabidopsis NLR immune signaling via $\mathrm{Ca}^{2+}$-dependent protein kinases. PLoS Pathog. 9:e1003127. doi: 10.1371/journal.ppat.1003127

Garcion, C., Lohmann, A., Lamodiere, E., Catinot, J., Buchala, A., Doermann, P., et al. (2008). Characterization and biological function of the ISOCHORISMATE SYNTHASE2 gene of Arabidopsis. Plant Physiol. 147, 1279-1287. doi: $10.1104 /$ pp.108.119420 
Gatz, C. (2013). From pioneers to team players: TGA transcription factors provide a molecular link between different stress pathways. Mol. Plant Microbe Interact. 26, 151-159. doi: 10.1094/MPMI-04-12-0078-IA

Gimenez-Ibanez, S., Boter, M., Fernandez-Barbero, G., Chini, A., Rathjen, J. P., and Solano, R. (2014). The bacterial effector HopX1 targets JAZ transcriptional repressors to activate jasmonate signaling and promote infection in Arabidopsis. PLoS Biol. 12:e1001792. doi: 10.1371/journal.pbio.1001792

Han, L., Li, G. J., Yang, K. Y., Mao, G., Wang, R., Liu, Y., et al. (2010). Mitogen-activated protein kinase 3 and 6 regulate Botrytis cinerea-induced ethylene production in Arabidopsis. Plant J. 64, 114-127. doi: 10.1111/j.1365313X.2010.04318.x

Hepworth, S. R., Zhang, Y., Mckim, S., Li, X., and Haughn, G. W. (2005). BLADE-ON-PETIOLE-dependent signaling controls leaf and floral patterning in Arabidopsis. Plant Cell 17, 1434-1448. doi: 10.1105/tpc.104.030536

Hermann, M., Maier, F., Masroor, A., Hirth, S., Pfitzner, A. J., and Pfitzner, U. M. (2013). The Arabidopsis NIMIN proteins affect NPR1 differentially. Front. Plant Sci. 4:88. doi: 10.3389/fpls.2013.00088

Hoehenwarter, W., Thomas, M., Nukarinen, E., Egelhofer, V., Rohrig, H., Weckwerth, W., et al. (2013). Identification of novel in vivo MAP kinase substrates in Arabidopsis thaliana through use of tandem metal oxide affinity chromatography. Mol. Cell. Proteomics 12, 369-380. doi: 10.1074/mcp.M112. 020560

Huang, J., Gu, M., Lai, Z., Fan, B., Shi, K., Zhou, Y. H., et al. (2010). Functional analysis of the Arabidopsis PAL gene family in plant growth, development, and response to environmental stress. Plant Physiol. 153, 1526-1538. doi: $10.1104 / p p .110 .157370$

Ishihara, T., Sekine, K. T., Hase, S., Kanayama, Y., Seo, S., Ohashi, Y., et al. (2008). Overexpression of the Arabidopsis thaliana EDS5 gene enhances resistance to viruses. Plant Biol. 10, 451-461. doi: 10.1111/j.1438-8677.2008. 00050.x

Jacob, F., Vernaldi, S., and Maekawa, T. (2013). Evolution and conservation of plant NLR functions. Front. Immunol. 4:297. doi: 10.3389/fimmu.2013.00297

Jiang, S., Yao, J., Ma, K. W., Zhou, H., Song, J., He, S. Y., et al. (2013). Bacterial effector activates jasmonate signaling by directly targeting JAZ transcriptional repressors. PLoS Pathog. 9:e1003715. doi: 10.1371/journal.ppat.1003715

Johnson, C., Boden, E., and Arias, J. (2003). Salicylic acid and NPR1 induce the recruitment of trans-activating TGA factors to a defense gene promoter in Arabidopsis. Plant Cell 15, 1846-1858. doi: 10.1105/tpc.012211

Jones, J. D., and Dangl, J. L. (2006). The plant immune system. Nature 444, 323329. doi: $10.1038 /$ nature 05286

Kim, D. S., and Hwang, B. K. (2014). An important role of the pepper phenylalanine ammonia-lyase gene (PAL1) in salicylic acid-dependent signalling of the defence response to microbial pathogens. J. Exp. Bot. 65, 2295-2306. doi: $10.1093 / \mathrm{jxb} / \mathrm{eru} 109$

Kim, H. S., Park, H. C., Kim, K. E., Jung, M. S., Han, H. J., Kim, S. H., et al. (2012). A NAC transcription factor and SNI1 cooperatively suppress basal pathogen resistance in Arabidopsis thaliana. Nucleic Acids Res. 40, 9182-9192. doi: $10.1093 /$ nar/gks683

Kim, Y., Park, S., Gilmour, S. J., and Thomashow, M. F. (2013). Roles of CAMTA transcription factors and salicylic acid in configuring the low-temperature transcriptome and freezing tolerance of Arabidopsis. Plant J. 75, 364-376. doi: $10.1111 /$ tpj. 12205

Kim, Y., Tsuda, K., Igarashi, D., Hillmer, R. A., Sakakibara, H., Myers, C. L., et al. (2014). Mechanisms underlying robustness and tunability in a plant immune signaling network. Cell Host Microbe 15, 84-94. doi: 10.1016/j.chom.2013.12.002

Kinkema, M., Fan, W., and Dong, X. (2000). Nuclear localization of NPR1 is required for activation of PR gene expression. Plant Cell 12, 2339-2350. doi: 10.1105/tpc.12.12.2339

Kumar, D., and Klessig, D. F. (2003). High-affinity salicylic acid-binding protein 2 is required for plant innate immunity and has salicylic acidstimulated lipase activity. Proc. Natl. Acad. Sci. U.S.A. 100, 16101-16106. doi: 10.1073/pnas. 0307162100

Li, G., Meng, X., Wang, R., Mao, G., Han, L., Liu, Y., et al. (2012). Dual-level regulation of ACC synthase activity by MPK3/MPK6 cascade and its downstream WRKY transcription factor during ethylene induction in Arabidopsis. PLoS Genet. 8:e1002767. doi: 10.1371/journal.pgen.1002767

Li, X., Zhang, Y., Clarke, J. D., Li, Y., and Dong, X. (1999). Identification and cloning of a negative regulator of systemic acquired resistance, SNI1, through a screen for suppressors of npr1-1. Cell 98, 329-339. doi: 10.1016/S0092-8674(00) 81962-5

Liu, T., Song, T., Zhang, X., Yuan, H., Su, L., Li, W., et al. (2014). Unconventionally secreted effectors of two filamentous pathogens target plant salicylate biosynthesis. Nat. Commun. 5, 4686. doi: 10.1038/ncomms5686

Lohou, D., Lonjon, F., Genin, S., and Vailleau, F. (2013). Type III chaperones \& Co in bacterial plant pathogens: a set of specialized bodyguards mediating effector delivery. Front. Plant Sci. 4:435. doi: 10.3389/fpls.2013.00435

Macho, A. P., and Zipfel, C. (2014). Plant PRRs and the activation of innate immune signaling. Mol. Cell 54, 263-272. doi: 10.1016/j.molcel.2014.03.028

Mao, G., Meng, X., Liu, Y., Zheng, Z., Chen, Z., and Zhang, S. (2011). Phosphorylation of a WRKY transcription factor by two pathogen-responsive MAPKs drives phytoalexin biosynthesis in Arabidopsis. Plant Cell 23, 1639-1653. doi: 10.1105/tpc.111.084996

Mauch, F., Mauch-Mani, B., Gaille, C., Kull, B., Haas, D., and Reimmann, C. (2001). Manipulation of salicylate content in Arabidopsis thaliana by the expression of an engineered bacterial salicylate synthase. Plant J. 25, 67-77. doi: 10.1046/j.1365-313x.2001.00940.x

Meng, X., Xu, J., He, Y., Yang, K. Y., Mordorski, B., Liu, Y., et al. (2013). Phosphorylation of an ERF transcription factor by Arabidopsis MPK3/MPK6 regulates plant defense gene induction and fungal resistance. Plant Cell 25, 1126-1142. doi: $10.1105 /$ tpc. 112.109074

Mine, A., Sato, M., and Tsuda, K. (2014). Toward a systems understanding of plantmicrobe interactions. Front. Plant Sci. 5:423. doi: 10.3389/fpls.2014.00423

Moreau, M., Westlake, T., Zampogna, G., Popescu, G., Tian, M., Noutsos, C., et al. (2013). The Arabidopsis oligopeptidases TOP1 and TOP2 are salicylic acid targets that modulate SA-mediated signaling and the immune response. Plant $J$. 76, 603-614. doi: 10.1111/tpj.12320

Mosher, R. A., Durrant, W. E., Wang, D., Song, J., and Dong, X. (2006). A comprehensive structure-function analysis of Arabidopsis SNI1 defines essential regions and transcriptional repressor activity. Plant Cell 18, 1750-1765. doi: 10.1105/tpc.105.039677

Mou, Z., Fan, W., and Dong, X. (2003). Inducers of plant systemic acquired resistance regulate NPR1 function through redox changes. Cell 113, 935-944. doi: 10.1016/S0092-8674(03)00429-X

Nawrath, C., Heck, S., Parinthawong, N., and Metraux, J. P. (2002). EDS5, an essential component of salicylic acid-dependent signaling for disease resistance in Arabidopsis, is a member of the MATE transporter family. Plant Cell 14, 275 286.

Nobuta, K., Okrent, R. A., Stoutemyer, M., Rodibaugh, N., Kempema, L., Wildermuth, M. C., et al. (2007). The GH3 acyl adenylase family member PBS3 regulates salicylic acid-dependent defense responses in Arabidopsis. Plant Physiol. 144, 1144-1156. doi: 10.1104/pp.107.097691

Okrent, R. A., Brooks, M. D., and Wildermuth, M. C. (2009). Arabidopsis GH3.12 (PBS3) conjugates amino acids to 4-substituted benzoates and is inhibited by salicylate. J. Biol. Chem. 284, 9742-9754. doi: 10.1074/jbc.M806662200

Pajerowska-Mukhtar, K. M., Emerine, D. K., and Mukhtar, M. S. (2013). Tell me more: roles of NPRs in plant immunity. Trends Plant Sci. 18, 402-411. doi: 10.1016/j.tplants.2013.04.004

Pajerowska-Mukhtar, K. M., Wang, W., Tada, Y., Oka, N., Tucker, C. L., Fonseca, J. P., et al. (2012). The HSF-like transcription factor TBF1 is a major molecular switch for plant growth-to-defense transition. Curr. Biol. 22, 103-112. doi: 10.1016/j.cub.2011.12.015

Park, S. W., Liu, P. P., Forouhar, F., Vlot, A. C., Tong, L., Tietjen, K., et al. (2009). Use of a synthetic salicylic acid analog to investigate the roles of methyl salicylate and its esterases in plant disease resistance. J. Biol. Chem. 284, 7307-7317. doi: 10.1074/jbc.M807968200

Pieterse, C. M., Van Der Does, D., Zamioudis, C., Leon-Reyes, A., and Van Wees, S. C. (2012). Hormonal modulation of plant immunity. Annu. Rev. Cell Dev. Biol. 28, 489-521. doi: 10.1146/annurev-cellbio-092910-154055

Poovaiah, B. W., Du, L., Wang, H., and Yang, T. (2013). Recent advances in calcium/calmodulin-mediated signaling with an emphasis on plantmicrobe interactions. Plant Physiol. 163, 531-542. doi: 10.1104/pp.113. 220780

Popescu, S. C., Popescu, G. V., Bachan, S., Zhang, Z., Gerstein, M., Snyder, M., et al. (2009). MAPK target networks in Arabidopsis thaliana revealed using functional protein microarrays. Genes Dev. 23, 80-92. doi: 10.1101/gad.1740009

Rabe, F., Ajami-Rashidi, Z., Doehlemann, G., Kahmann, R., and Djamei, A. (2013). Degradation of the plant defence hormone salicylic acid by the biotrophic 
fungus Ustilago maydis. Mol. Microbiol. 89, 179-188. doi: 10.1111/mmi. 12269

Robert-Seilaniantz, A., Grant, M., and Jones, J. D. (2011). Hormone crosstalk in plant disease and defense: more than just jasmonate-salicylate antagonism. Annu. Rev. Phytopathol. 49, 317-343. doi: 10.1146/annurev-phyto-073009114447

Rochon, A., Boyle, P., Wignes, T., Fobert, P. R., and Despres, C. (2006). The coactivator function of Arabidopsis NPR1 requires the core of its BTB/POZ domain and the oxidation of C-terminal cysteines. Plant Cell 18, 3670-3685. doi: 10.1105/tpc.106.046953

Rushton, P. J., Somssich, I. E., Ringler, P., and Shen, Q. J. (2010). WRKY transcription factors. Trends Plant Sci. 15, 247-258. doi: 10.1016/j.tplants.2010.02.006

Sadeghi, M., Dehghan, S., Fischer, R., Wenzel, U., Vilcinskas, A., Kavousi, H. R., et al. (2013). Isolation and characterization of isochorismate synthase and cinnamate 4-hydroxylase during salinity stress, wounding, and salicylic acid treatment in Carthamus tinctorius. Plant Signal. Behav. 8:e27335. doi: 10.4161/psb.27335

Schulz, P., Herde, M., and Romeis, T. (2013). Calcium-dependent protein kinases: hubs in plant stress signaling and development. Plant Physiol. 163, 523-530. doi: 10.1104/pp.113.222539

Serrano, M., Wang, B., Aryal, B., Garcion, C., Abou-Mansour, E., Heck, S., et al. (2013). Export of salicylic acid from the chloroplast requires the multidrug and toxin extrusion-like transporter EDS5. Plant Physiol. 162, 1815-1821. doi: 10.1104/pp.113.218156

Shah, J., Tsui, F., and Klessig, D. F. (1997). Characterization of a salicylic acidinsensitive mutant (sail) of Arabidopsis thaliana, identified in a selective screen utilizing the SA-inducible expression of the tms2 gene. Mol. Plant Microbe Interact. 10, 69-78. doi: 10.1094/MPMI.1997.10.1.69

Slaymaker, D. H., Navarre, D. A., Clark, D., del Pozo, O., Martin, G. B., and Klessig, D. F. (2002). The tobacco salicylic acid-binding protein 3 (SABP3) is the chloroplast carbonic anhydrase, which exhibits antioxidant activity and plays a role in the hypersensitive defense response. Proc. Natl. Acad. Sci. U.S.A. 99, 11640-11645. doi: 10.1073/pnas.182427699

Song, J., and Bent, A. F. (2014). Microbial pathogens trigger host DNA doublestrand breaks whose abundance is reduced by plant defense responses. PLoS Pathog. 10:e1004030. doi: 10.1371/journal.ppat.1004030

Song, J., Durrant, W. E., Wang, S., Yan, S., Tan, E. H., and Dong, X. (2011). DNA repair proteins are directly involved in regulation of gene expression during plant immune response. Cell Host Microbe 9, 115-124. doi: 10.1016/j.chom.2011.01.011

Spoel, S. H., Koornneef, A., Claessens, S. M., Korzelius, J. P., Van Pelt, J. A., Mueller, M. J., et al. (2003). NPR1 modulates cross-talk between salicylate- and jasmonate-dependent defense pathways through a novel function in the cytosol. Plant Cell 15, 760-770. doi: 10.1105/tpc.009159

Spoel, S. H., Mou, Z., Tada, Y., Spivey, N. W., Genschik, P., and Dong, X. (2009). Proteasome-mediated turnover of the transcription coactivator NPR1 plays dual roles in regulating plant immunity. Cell 137, 860-872. doi: 10.1016/j.cell.2009.03.038

Strawn, M. A., Marr, S. K., Inoue, K., Inada, N., Zubieta, C., and Wildermuth, M. C. (2007). Arabidopsis isochorismate synthase functional in pathogen-induced salicylate biosynthesis exhibits properties consistent with a role in diverse stress responses. J. Biol. Chem. 282, 5919-5933. doi: 10.1074/jbc.M605193200

Tada, Y., Spoel, S. H., Pajerowska-Mukhtar, K., Mou, Z., Song, J., Wang, C., et al. (2008). Plant immunity requires conformational changes [corrected] of NPR1 via S-nitrosylation and thioredoxins. Science 321, 952-956. doi: 10.1126/science. 1156970

Tian, M., Von Dahl, C. C., Liu, P. P., Friso, G., Van Wijk, K. J., and Klessig, D. F. (2012). The combined use of photoaffinity labeling and surface plasmon resonance-based technology identifies multiple salicylic acid-binding proteins. Plant J. 72, 1027-1038. doi: 10.1111/tpj.12016

Tripathi, D., Jiang, Y. L., and Kumar, D. (2010). SABP2, a methyl salicylate esterase is required for the systemic acquired resistance induced by acibenzolar- $S$-methyl in plants. FEBS Lett. 584, 3458-3463. doi: 10.1016/j.febslet.2010.06.046

Truman, W., Sreekanta, S., Lu, Y., Bethke, G., Tsuda, K., Katagiri, F., et al. (2013). The CALMODULIN-BINDING PROTEIN60 family includes both negative and positive regulators of plant immunity. Plant Physiol. 163, 1741-1751. doi: 10.1104/pp.113.227108

Tsuda, K., Glazebrook, J., and Katagiri, F. (2008a). The interplay between MAMP and SA signaling. Plant Signal. Behav. 3, 359-361. doi: 10.4161/psb.3.6.5702
Tsuda, K., Sato, M., Glazebrook, J., Cohen, J. D., and Katagiri, F. (2008b). Interplay between MAMP-triggered and SA-mediated defense responses. Plant J. 53, $763-$ 775. doi: 10.1111/j.1365-313X.2007.03369.x

Tsuda, K., and Katagiri, F. (2010). Comparing signaling mechanisms engaged in pattern-triggered and effector-triggered immunity. Curr. Opin. Plant Biol. 13, 459-465. doi: 10.1016/j.pbi.2010.04.006

Tsuda, K., Mine, A., Bethke, G., Igarashi, D., Botanga, C. J., Tsuda, Y., et al. (2013). Dual regulation of gene expression mediated by extended MAPK activation and salicylic acid contributes to robust innate immunity in Arabidopsis thaliana. PLoS Genet. 9:e1004015. doi: 10.1371/journal.pgen.1004015

Uppalapati, S. R., Ishiga, Y., Wangdi, T., Kunkel, B. N., Anand, A., Mysore, K. S., et al. (2007). The phytotoxin coronatine contributes to pathogen fitness and is required for suppression of salicylic acid accumulation in tomato inoculated with Pseudomonas syringae pv. tomato DC3000. Mol. Plant Microbe Interact. 20, 955-965. doi: 10.1094/MPMI-20-8-0955

van Verk, M. C., Bol, J. F., and Linthorst, H. J. (2011). WRKY transcription factors involved in activation of SA biosynthesis genes. BMC Plant Biol. 11:89. doi: 10.1186/1471-2229-11-89

Verberne, M. C., Verpoorte, R., Bol, J. F., Mercado-Blanco, J., and Linthorst, H. J. (2000). Overproduction of salicylic acid in plants by bacterial transgenes enhances pathogen resistance. Nat. Biotechnol. 18, 779-783. doi: 10.1038/77347

Vlot, A. C., Dempsey, D. A., and Klessig, D. F. (2009). Salicylic Acid, a multifaceted hormone to combat disease. Annu. Rev. Phytopathol. 47, 177-206. doi: 10.1146/annurev.phyto.050908.135202

Volko, S. M., Boller, T., and Ausubel, F. M. (1998). Isolation of new Arabidopsis mutants with enhanced disease susceptibility to Pseudomonas syringae by direct screening. Genetics 149, 537-548.

Wan, D., Li, R., Zou, B., Zhang, X., Cong, J., Wang, R., et al. (2012). Calmodulinbinding protein CBP60g is a positive regulator of both disease resistance and drought tolerance in Arabidopsis. Plant Cell Rep. 31, 1269-1281. doi: 10.1007/s00299-012-1247-7

Wang, D., Amornsiripanitch, N., and Dong, X. (2006). A genomic approach to identify regulatory nodes in the transcriptional network of systemic acquired resistance in plants. PLoS Pathog. 2:e123. doi: 10.1371/journal.ppat.0020123

Wang, L., and Fobert, P. R. (2013). Arabidopsis clade I TGA factors regulate apoplastic defences against the bacterial pathogen Pseudomonas syringae through endoplasmic reticulum-based processes. PLOS ONE 8:e77378. doi: 10.1371/journal. pone. 0077378

Wang, L., Tsuda, K., Sato, M., Cohen, J. D., Katagiri, F., and Glazebrook, J. (2009). Arabidopsis CaM binding protein CBP60g contributes to MAMP-induced SA accumulation and is involved in disease resistance against Pseudomonas syringae. PLoS Pathog. 5:e1000301. doi: 10.1371/journal.ppat.1000301

Wang, L., Tsuda, K., Truman, W., Sato, M., Nguyen Le, V., Katagiri, F., et al. (2011). CBP60g and SARD1 play partially redundant critical roles in salicylic acid signaling. Plant J. 67, 1029-1041. doi: 10.1111/j.1365-313X.2011. 04655.x

Wang, S., Durrant, W. E., Song, J., Spivey, N. W., and Dong, X. (2010). Arabidopsis BRCA2 and RAD51 proteins are specifically involved in defense gene transcription during plant immune responses. Proc. Natl. Acad. Sci. U.S.A. 107, 2271622721. doi: 10.1073/pnas.1005978107

Weigel, R. R., Pfitzner, U. M., and Gatz, C. (2005). Interaction of NIMIN1 with NPR1 modulates PR gene expression in Arabidopsis. Plant Cell 17, 1279-1291. doi: 10.1105/tpc.104.027441

Westfall, C. S., Herrmann, J., Chen, Q., Wang, S., and Jez, J. M. (2010). Modulating plant hormones by enzyme action: the GH3 family of acyl acid amido synthetases. Plant Signal. Behav. 5, 1607-1612. doi: 10.4161/psb.5.12. 13941

Westfall, C. S., Zubieta, C., Herrmann, J., Kapp, U., Nanao, M. H., and Jez, J. M. (2012). Structural basis for prereceptor modulation of plant hormones by GH3 proteins. Science 336, 1708-1711. doi: 10.1126/science.1221863

Wildermuth, M. C., Dewdney, J., Wu, G., and Ausubel, F. M. (2001). Isochorismate synthase is required to synthesize salicylic acid for plant defence. Nature 414, 562-565. doi: 10.1038/35107108

Wu, Y., Zhang, D., Chu, J. Y., Boyle, P., Wang, Y., Brindle, I. D., et al. (2012). The Arabidopsis NPR1 protein is a receptor for the plant defense hormone salicylic acid. Cell Rep. 1, 639-647. doi: 10.1016/j.celrep.2012.05.008

Xin, X. F., and He, S. Y. (2013). Pseudomonas syringae pv. tomato DC3000: a model pathogen for probing disease susceptibility and hormone signaling 
in plants. Annu. Rev. Phytopathol. 51, 473-498. doi: 10.1146/annurev-phyto082712-102321

Yan, S., and Dong, X. (2014). Perception of the plant immune signal salicylic acid. Curr. Opin. Plant Biol. 20C, 64-68. doi: 10.1016/j.pbi.2014.04.006

Yan, S., Wang, W., Marques, J., Mohan, R., Saleh, A., Durrant, W. E., et al. (2013). Salicylic acid activates DNA damage responses to potentiate plant immunity. Mol. Cell 52, 602-610. doi: 10.1016/j.molcel.2013.09.019

Yu, D., Chen, C., and Chen, Z. (2001). Evidence for an important role of WRKY DNA binding proteins in the regulation of NPR1 gene expression. Plant Cell 13, 1527-1540. doi: 10.1105/tpc.13.7.1527

Yuan, Y., Chung, J. D., Fu, X., Johnson, V. E., Ranjan, P., Booth, S. L., et al. (2009). Alternative splicing and gene duplication differentially shaped the regulation of isochorismate synthase in Populus and Arabidopsis. Proc. Natl. Acad. Sci. U.S.A. 106, 22020-22025. doi: 10.1073/pnas.0906869106

Zhang, L., Du, L., Shen, C., Yang, Y., and Poovaiah, B. W. (2014). Regulation of plant immunity through ubiquitin-mediated modulation of $\mathrm{Ca}^{2+}$ calmodulin-AtSR1/CAMTA3 signaling. Plant J. 78, 269-281. doi: 10.1111/tpj. 12473

Zhang, Y., Tessaro, M. J., Lassner, M., and Li, X. (2003). Knockout analysis of Arabidopsis transcription factors TGA2, TGA5, and TGA6 reveals their redundant and essential roles in systemic acquired resistance. Plant Cell 15, 2647-2653. doi: $10.1105 /$ tpc.014894

Zhang, Y., Xu, S., Ding, P., Wang, D., Cheng, Y. T., He, J., et al. (2010). Control of salicylic acid synthesis and systemic acquired resistance by two members of a plant-specific family of transcription factors. Proc. Natl. Acad. Sci. U.S.A. 107, 18220-18225. doi: 10.1073/pnas.1005225107

Zhang, Z., Li, Q., Li, Z., Staswick, P. E., Wang, M., Zhu, Y., et al. (2007). Dual regulation role of GH3.5 in salicylic acid and auxin signaling during Arabidopsis-Pseudomonas syringae interaction. Plant Physiol. 145, 450-464. doi: 10.1104/pp.107.106021

Zheng, X. Y., Spivey, N. W., Zeng, W., Liu, P. P., Fu, Z. Q., Klessig, D. F., et al. (2012). Coronatine promotes Pseudomonas syringae virulence in plants by activating a signaling cascade that inhibits salicylic acid accumulation. Cell Host Microbe 11, 587-596. doi: 10.1016/j.chom.2012.04.014

Zheng, Z., Qualley, A., Fan, B., Dudareva, N., and Chen, Z. (2009). An important role of a BAHD acyl transferase-like protein in plant innate immunity. Plant J. 57, 1040-1053. doi: 10.1111/j.1365-313X.2008. 03747.x

Zhou, J. M., Trifa, Y., Silva, H., Pontier, D., Lam, E., Shah, J., et al. (2000). NPR1 differentially interacts with members of the TGA/OBF family of transcription factors that bind an element of the PR-1 gene required for induction by salicylic acid. Mol. Plant Microbe Interact. 13, 191-202. doi: 10.1094/MPMI.2000.13.2.191

Zhou, N., Tootle, T. L., Tsui, F., Klessig, D. F., and Glazebrook, J. (1998). PAD4 functions upstream from salicylic acid to control defense responses in Arabidopsis. Plant Cell 10, 1021-1030. doi: 10.1105/tpc.10.6.1021

Conflict of Interest Statement: The authors declare that the research was conducted in the absence of any commercial or financial relationships that could be construed as a potential conflict of interest.

Received: 15 October 2014; accepted: 24 November 2014; published online: 09 December 2014.

Citation: Seyfferth C and Tsuda K (2014) Salicylic acid signal transduction: the initiation of biosynthesis, perception and transcriptional reprogramming. Front. Plant Sci. 5:697. doi: 10.3389/fpls.2014.00697

This article was submitted to Plant-Microbe Interaction, a section of the journal Frontiers in Plant Science.

Copyright $\odot 2014$ Seyfferth and Tsuda. This is an open-access article distributed under the terms of the Creative Commons Attribution License (CC BY). The use, distribution or reproduction in other forums is permitted, provided the original author(s) or licensor are credited and that the original publication in this journal is cited, in accordance with accepted academic practice. No use, distribution or reproduction is permitted which does not comply with these terms. 